delivery should be based on the woman's risk factors. Earlier induction of labour would obviously be preferable for a 40 year old primigravid woman with a long history of infertility, even after an uncomplicated pregnancy, whereas it may be inappropriate for a 25 year old multiparous woman.

The state of the cervix (Bishop's score) should also be considered. If delivery with an unfavourable cervix is thought essential it may be better to deliver by elective lower segment caesarean section under epidural block than to risk the need for an emergency caesarean section under general anaesthesia in the middle of the night. Emergency caesareans carry a much higher risk of morbidity and mortality to the mother and asphyxia to the baby. Recent data from King's College Hospital have shown an unacceptable incidence of unrecognised maternal morbidity associated with caesarean section and this may be compounded by the need for repeated operative delivery in subsequent pregnancies. ${ }^{9}$

\section{Alternatives to induction}

Is there anything we can do for women who go past term? Membrane stripping has been suggested to produce earlier spontaneous labour and have no complications, ${ }^{10}$ but it is also an intervention that many women would dislike. The best policy is probably to offer increased fetal surveillance after 42 weeks (or earlier if risk factors are present) and to terminate the pregnancy if adverse features occur. Pearce and McParland showed that the most sensitive measure in antenatal fetal surveillance is absence of end diastolic frequencies in the umbilical artery (assessed by Doppler ultrasonography). ${ }^{11}$ This predicted $91 \%$ of fetuses who became distressed in the first stage of labour, and combination with ultrasonographic estimation of the volume of amniotic fluid improved prediction to $100 \%$ with only a slight fall in specificity.

Perhaps the most important part of managing postterm pregnancy is involving the woman and her partner. The decision to induce or not should be discussed, and if possible the woman's views respected. I discuss induction of labour at 42 weeks' gestation in an otherwise uncomplicated pregnancy and offer it if the cervix is favourable and the woman keen to be delivered. I encourage women to have induction at 43 weeks' gestation because of the slightly increased risk to the baby thereafter. Unfortunately, there is no "right time" to induce nor any conclusive data on which to base a rational decision.

1 Boyd ME, Usher RH, McClem FH, Kramer MS. Obstetric consequences of postmaturity. Am Y Obstet Gynecol 1988;158:334-8.

2 Gibb DMF, Cardozo LD, Studd JWW, Cooper DJ. Prolonged pregnancy: is induction of labour indicated? A prospective study. Br $\mathcal{F}$ Obstet Gynaecol 1982;89:292-5.

3 Cardozo LD, Fysh J, Pearce JM. Prolonged pregnancy-the management debate. $B M \mathcal{F}$ 1986;293:1059-63.

4 Hannah ME, Hannah WJ, Hellmann J, Hewson S, Milner R, Willan A and the Canadian multicenter post-term pregnancy trial group. Induction of labor as Canadian multicenter post-term pregnancy trial group. Induction of labor as
compared with serial antenatal monitoring in post-term pregnancy. A compared with serial antenatal monitoring in post-term

5 Saunders N, Paterson C. Effect of gestational age on obstetric performance: when is "term" over? Lancet 1991;338:1190-2.

6 Chapatte O, Versi E. Gestational age and obstetric performance. Lancet 1992;339:122.

7 Bergsjo P, Gui-dan H, Su-qui Y, Zhi-zeng G, Bakketeig LS. Comparison of induced versus non-induced labor in post-term pregnancy. Acta Obstet Gynecol Scand 1989;68:683-7.

8 Augensen K, Bergsjo P, Eikeland T, Askrik K, Carlsen J. Randomised comparison of early versus late induction of labour in post-term pregnancy. BMf 1987;294:1192-5.

9 Kelleher C, Cardozo LD. Caesarean section-unrecognised morbidity. 7 Obstet Gynaecol (in press).

10 McColgin SW, Hampton HL, McCaul JF, Howard PR, Andrew ME, Morrison JC. Stripping membranes at term: can it safely reduce the incidence of post-term pregnancies? Obstet Gynecol 1990;76:678-80.

11 Pearce JM, McParland PJ. A comparison of Doppler flow velocity waveforms, amniotic fluid columns and non-stress test as a means of monitoring postdate pregnancies. Obstet Gynecol 1991;77:204-8.

(Accepted 28 January 1993)

\title{
Acute haemolysis induced by high dose ascorbic acid in glucose-6-phosphate dehydrogenase deficiency
}

\author{
D C Rees, H Kelsey, J D M Richards
}

High dose ascorbic acid can cause haemolysis in glucose6-phosphate dehydrogenase deficiency

\section{Department of Haematology, University College Hospital, London WC1E 6AU \\ D C Rees, registrar in haematology \\ $\mathrm{H}$ Kelsey, research fellow in haematology \\ JD M Richards, consultant in haematology}

Correspondence to: Dr Richards.

$B M 7$ 1993;306:841-2
The use of high dose ascorbic acid (vitamin C) has been advocated for a wide range of ailments for years. Such treatments are generally thought to have few adverse effects and are often self administered. We present a case illustrating the particular caution necessary in subjects at risk of glucose-6-phosphate dehydrogenase deficiency.

\section{Case report}

A 32 year old man born in Britain of Nigerian parents was admitted as an emergency case complaining of breathlessness, dark urine, and left subcostal pain radiating to the left shoulder. His history included malaria caught in Nigeria at the age of 11 and treated uneventfully with quinine. There was no family history of haemolytic crises and he had been healthy until December 1991, when he was found to have antibodies to HIV-1. There were no known risk factors for HIV infection. The exact source of the infection was unclear. His CD4 lymphocyte count was $0.35 \times 10^{\circ} / 1$. He had remained well until June 1992 , when he developed generalised lymphadenopathy and his doctors recommended that he should start zido- vudine. He had refused, however, and sought advice privately from a medically qualified nutritionist. An extensive nutritional screen was performed, including measurements of blood mineral, vitamin, and fatty acid concentrations. Among several abnormalities noted were low serum and red cell glutathione concentrations (red cell glutathione $1.1 \mathrm{mmol} / \mathrm{l}$ (normal $1 \cdot 6-2.8 \mathrm{mmol} / \mathrm{l})$, serum glutathione $3.2 \mu \mathrm{mol} / \mathrm{h}$ (normal 3.8-8.2 $\mu \mathrm{mol} / \mathrm{l}$ )).

He was prescribed a course of multivitamins, essential fatty acids, and glutathione supplements. He was also prescribed a course of high dose intravenous ascorbic acid, $40 \mathrm{~g}$ three times weekly, supplemented by $20-40 \mathrm{~g}$ ascorbic acid daily by mouth. This proceeded uneventfully for about a month with no obvious evidence of either haemolysis or regression of lymphadenopathy. The intravenous dose was increased to $80 \mathrm{~g}$, and next day the patient became breathless and feverish and noticed that his urine was black. His symptoms worsened over the next two days and he returned to the nutritionist.

Results of blood tests were: haemoglobin concentration $67 \mathrm{~g} /$, white cell count $12 \cdot 7 \times 10^{\circ} /$, platelet count $198 \times 10^{\circ} /$, reticulocyte count $15.6 \%$, bilirubin concen- 
tration $54 \mu \mathrm{mol} / 1$ (conjugated bilirubin $13 \mu \mathrm{mol} / \mathrm{l}$ ), hydroxybutyrate dehydrogenase activity 557 IU/1 (normal 100-280 IU/1), alkaline phosphatase activity $104 \mathrm{IU} / \mathrm{l}$ (normal 100-280 IU//), creatinine concentration $93 \mu \mathrm{mol} / \mathrm{l}$, urea concentration $7.3 \mathrm{mmol} / /$, sodium concentration $136 \mathrm{mmol} / \mathrm{l}$, and potassium concentration $4.5 \mathrm{mmol} / \mathrm{l}$. His coagulation screen was normal. Blood was detected in the urine on biochemical screening, but microscopy showed very few red cells. A blood film showed changes typical of oxidative haemolysis.

He was admitted to hospital and encouraged to drink 4-5 litres of fluid daily with careful monitoring of renal function. He was given folic acid by mouth. A glucose6-phosphate dehydrogenase assay performed on reticulocyte depleted blood confirmed deficiency with a value of $1.8 \mathrm{IU} / \mathrm{g}$ haemoglobin (normal 5.9-11.8 IU/g). Haemoglobin electrophoresis showed sickle cell trait.

The haemoglobin concentration continued to fall for two days after his admission, reaching a nadir of $61 \mathrm{~g} / 1$. On the third day his urine was clear and his renal function remained normal. He made an uneventful recovery and was discharged home after four days.

\section{Discussion}

Ascorbic acid has been used in pharmacological doses for more than 20 years. ${ }^{1}$ It has been proposed as useful in a wide range of conditions, including hypertension, colds, HIV infection, hepatitis A and hepatitis B, myocardial infarction, cancer, cataract, asthma, Parkinson's disease, schizophrenia, arthritis, cystinuria, alkaptonuria, myeloma, leukaemia, iron overload, methaemoglobinaemia, and immune thrombocytopenic purpura. The evidence supporting its use in these conditions is variable, but there are few adequate clinical trials suggesting definite benefit. In general the ascorbic acid is thought to act as a free radical scavenger or by a direct antiviral effect.

Its use in HIV infection stems from anecdotal reports of clinical benefit after high dose ascorbic acid ${ }^{2}$ and from subsequent in vitro experiments showing suppression of HIV replication in chronically infected T lymphocytes. ${ }^{3}$ There are no published trials proving its clinical efficacy.

Despite little definite evidence supporting the use of high dose ascorbic acid, it is widely favoured by doctors and patients as healthy, natural, and without appreciable side effects. Reported contraindications include renal insufficiency, chronic haemodialysis, some forms of iron overload, and previous oxalate stone formation. ${ }^{4}$ We could find no reference to caution in people at risk of glucose-6-phosphate dehydrogenase deficiency. However, there have been two case reports of haemolytic crises caused by ascorbic acid. One concerned a black American man given $80 \mathrm{~g}$ ascorbic acid intravenously for burns; he subsequently developed acute haemolysis and renal failure and died. ${ }^{5}$ The second report concerned two boys in India who developed acute haemolysis after a "binge of fizzy drinks" containing 4-6 g ascorbic acid. ${ }^{6}$

Glucose-6-phosphate dehydrogenase is an extremely polymorphic enzyme, essential in the metabolism of glucose and the production of reduced nicotinamide adenine dinucleotide phosphate in the hexose-monophosphate shunt, ${ }^{7}$ essential in the generation of reduced glutathione in the red cell for protection against oxidative stress. The gene is found on the $\mathrm{X}$ chromosome, males being more severely affected than females. Females may be variably affected by virtue of random inactivation of the $\mathrm{X}$ chromosome. Roughly $10 \%$ of black Americans were found to have the mildly defective A glucose-6-phosphate dehydrogenase variant, more severe $B$ variants occurring around the Mediterranean and in South East Asia. It is the commonest enzymopathy affecting erythrocytes.

Affected subjects may be detected either by simple visual fluorescence or colorimetric screening tests or by direct assay of enzyme activity. Acute haemolytic crises usually result from exposure to oxidant drugs, fava beans, bacterial or viral infections, or severe acidosis-for example, diabetic ketoacidosis. It is perhaps surprising, therefore, that ascorbic acid, a known reducing agent, can precipitate haemolysis. However, there were no other factors in our patient to account for the acute haemolytic episode, and ascorbic acid induced haemolysis in glucose-6-phosphate dehydrogenase deficiency has been reported. Indeed, low concentrations of ascorbate have been shown to protect against haemolysis of glucose-6-phosphate dehydrogenase deficient erythrocytes in vitro. ${ }^{8}$ However, higher concentrations were shown to produce haemolysis. A study in rats showed reduced survival of glucose-6-phosphate dehydrogenase deficient erythrocytes in the presence of ascorbic acid. ${ }^{9}$ The exact mechanism for ascorbate induced haemolysis in glucose-6-phosphate dehydrogenase deficiency is uncertain but is thought to entail generation of hydrogen peroxide and other reactive oxygen species, which rapidly exhaust the limited glutathione supply.

Of particular interest in this case is the fact that as part of a nutritional screen serum and red cell glutathione concentrations were measured and found to be low. Low glutathione concentrations have been associated with increased risk of progression to AIDS in HIV positive people. ${ }^{10}$ In our patient it seems probable that the low concentrations reflected the glucose-6phosphate dehydrogenase deficiency. It also seems plausible that the glutathione supplements might have protected the erythrocytes against oxidative stress, thus allowing the patient to tolerate up to $60 \mathrm{~g}$ ascorbic acid without appreciable haemolysis.

The indications for treatment with high dose ascorbic acid seem to be increasing. Some of the diseases supposedly benefiting from such treatment are common in areas where glucose-6-phosphate dehydrogenase deficiency is also common-for example, hepatitis B and HIV infection. Although ascorbic acid induced haemolysis has been described, the risk seems not to be widely appreciated, and indeed ascorbic acid does not occur on many lists of drugs to be avoided in glucose-6-phosphate dehydrogenase deficiency. ${ }^{11}$ It is important to screen people at risk of glucose-6phosphate dehydrogenase deficiency for this disorder before starting high dose ascorbic acid.

1 Wilson CMW, Loh HS. Vitamin C and colds. Lancet 1973;i:1058-9.

2 Cathcart $R$. Vitamin $C$ in the treatment of acquired immune deficiency syndrome (AIDS). Med Hypotheses 1984;14:423-33.

3 Harekeh S, Jariwalla RJ. Comparative study of the anti-HIV activities of ascorbate and thiol-containing reducing agents in chronically infected HIVinfected cells. Am f Clin Nutr 1991;54:1231-5S.

4 Rivers JM. Safety of high level vitamin C ingestion. Int 9 Vitam Nutr Res Suppl 1989;30:95-102.

5 Campbell G, Steinberg M, Bower D. Ascorbic acid-induced haemolysis in G-6-PD deficiency. Ann Intern Med 1975;82:810.

6 Mehta JB, Singhal SB, Meutch BC. Ascorbic acid induced haemolysis in G-6-PD deficiency. Lancet 1990;336:944.

7 Dacie J. The haemolytic anaemias. 3rd ed. Edinburgh: Churchill Livingstone, 1985:365-419.

8 Winterburn C. Protection by ascorbate against acetylphenyl-hydralazine induced Heinz body formation in glucose-6-phosphate dehydrogenase-
interburn deficient erythrocytes. Br f Haematol 1979;41:245-52.

9 Udomratn T, Steinberg G, Campbell D, Oelshlegal FJ. Effects of ascorbic acid on glucose-6-phosphate dehydrogenase-deficient erythrocytes: studies in an animal model. Blood 1977;49:471-5.

10 Buhl R, Holroyd KJ, Mastrangeli A. Systemic glutathione deficiency in symptom free HIV-seropositive individuals. Lancet 1989;ii:1294-8.

11 Hoffbrand AV, Lewis SM. Postgraduate haematology. 3rd ed. New York: Heinemann, 1989:146-82

(Accepted 28 January 1993) 